\title{
Nano-hardness and microstructure of selective laser melted AISi10Mg scan tracks
}

\author{
Nesma T. Aboulkhair ${ }^{\mathrm{a}^{*}}$, Ian Maskery ${ }^{\mathrm{b}}$, Chris Tuck ${ }^{\mathrm{b}}$, Ian Ashcroft ${ }^{\mathrm{b}}$, Nicola M. Everitt $^{\mathrm{a}}$ \\ ${ }^{\mathrm{a}}$ Materials, Mechanics and Structures Research Division, Faculty of Engineering, University of \\ Nottingham, Nottingham NG7 2RD, United Kingdom \\ ${ }^{\mathrm{b}}$ Manufacturing and Process Technologies Research Division, Faculty of Engineering, University of \\ Nottingham, Nottingham NG7 2RD, United Kingdom
}

\begin{abstract}
Selective laser melting (SLM) of aluminium alloys faces more challenges than other ongoing alloys such as stainless steels and titanium alloys because of the material's properties. It is important to study single scan tracks if high density large parts are to be made since they are the primary building blocks. In this study, the geometrical features of $\mathrm{AlSi} 10 \mathrm{Mg}$ tracks indicated keyhole mode melting domination. Chemical composition mapping and nanoindentation showed enhanced nano-hardness in SLM material over conventional material with no spatial variation. This is due to a homogeneous elemental distribution and fine microstructure developed by fast solidification.
\end{abstract}

Selective laser melting, single tracks, aluminium alloys, energy dispersive spectroscopy, nanoindentation.

\section{INTRODUCTION}

The use of lasers in manufacturing is now quite commonplace. Lasers gained consideration as machine tools and for use in the industrial processing of materials during the 1970s. Laser systems developed rapidly, promoting flexible manufacturing systems, in the $1980 \mathrm{~s}^{[1]}$. Selective laser melting is one of the additive manufacturing processes that utilize a laser for processing materials to produce parts from powder. In the process, a laser beam scans a powder-bed to selectively melt the powder according to information from a sliced CAD-file ${ }^{[2,3]}$. This is repeated successively layer-bylayer until the full part is manufactured.

The properties of the material to be laser processed have a dominant role on the process control as they govern lasermaterial interactions. Examples of these properties are the absorptivity, specific heat capacity, thermal conductivity, density, coefficient of thermal expansion, and phase and state transformation temperatures. A laser beam directed at a surface might be absorbed, reflected, or transmitted depending on the absorptivity of the material ${ }^{[1]}$. A thermal gradient develops in a material irradiated by a laser beam. On cooling, the coefficient of surface tension increases with temperature decrease. As a result of the surface tension gradient, fluid flows from the centre of the melt pool to the edges in what is known as the Marangoni flow. Marangoni flow is the dominant mechanism of convection in laser-induced melt pools ${ }^{[1]}$. The outcome from these reactions is the formation of a melt pool with shape dependent on the melting mode.

There have been several studies investigating the formation of single SLM tracks from metal powder. Most of the studies were concerned with defining the zones of consolidation and the formation of defects for materials such as $\mathrm{AlSi} 10 \mathrm{Mg}^{[4}$,

\footnotetext{
*Corresponding author: emxntab@nottingham.ac.uk
} 
5], stainless steel grade $304^{[6]}$, stainless steel grade $316 \mathrm{~L}^{[7]}$, and stainless steel grade $904 \mathrm{~L}^{[8]}$. During selective laser melting, the laser beam melts the powder line-by-line forming a consolidated layer from overlapping melt pools. The melt pool usually forms a circular or cylindrical segment. The stability of the melt pool is affected by the processing parameters such as laser power, scan speed, layer thickness, substrate material, and the properties of the powder ${ }^{[6]}$. The depth and width of a melt pool are controlled by the laser power and the scan speed ${ }^{[9]}$. Yadroitsev et al. ${ }^{[10]}$ reported the presence of satellites on top of stainless steel 316L single tracks that promote the creation of pores and worsen the surface roughness. Tracing the causes and mechanisms of porosity formation is important in this area of research. Dai and $\mathrm{Gu}^{[11]}$ proposed an hypothesis, based on modelling the process of selective laser melting of copper matrix composites, that pores form because of the entrapment of gaseous bubbles within each melt pool. However, this was not validated in their study.

The current study investigates the features of AlSi10Mg scan tracks processed using selective laser melting. The surface features as well as cross-sectional views were examined to determine if any defects were formed at the tested combination of processing parameters. The distribution of chemical elements within the melt pool was explored and related to the nano-hardness profile across the selective laser melted material. In addition, the issue of whether pores started to form in each individual melt pool was investigated.

\section{MATERIALS \& METHODS}

A Realizer GmbH SLM-50 (Germany) selective laser melting machine equipped with a 100W Yttrium fibre laser (YLM100-AC) was used to create single tracks in this study. Experiments were conducted in a controlled atmosphere chamber to avoid oxidation during the process, with the purging gas being argon. The oxygen level within the chamber was monitored to be kept below $0.1 \%$. The tracks were formed using a laser scan speed of $250 \mathrm{~mm} / \mathrm{s}$ and a $100 \mathrm{~W}$ laser power. Tracks were created from AlSi10Mg powder supplied by TLS Technik GmbH (Germany). Before processing, the powder was dried for 20 minutes at $70{ }^{\circ} \mathrm{C}$. The powder was specifically manufactured for additive manufacturing so it had a spherical morphology with minimal satellites, as can be seen in Figure 1. The chemical composition of the powder was $86.96 \mathrm{wt} \% \mathrm{Al}, 12.58 \mathrm{wt} \% \mathrm{Si}$, and $0.46 \mathrm{wt} \% \mathrm{Mg}$ as analysed by an energy dispersive spectrometer EDS attached to a Phillips XL30 scanning electron microscope. It is worth noting that the amount of Si in the powder was slightly higher than the standard composition for this alloy $(9-11 \mathrm{wt} \%)^{[12]}$, which might affect the melting and solidification behaviour. The thickness of the powder layer deposited was set to $40 \mu \mathrm{m}$. The tracks were formed on a polished LM6 (Al-Si12\%) substrate. The substrate was polished and cleaned with acetone prior to processing.

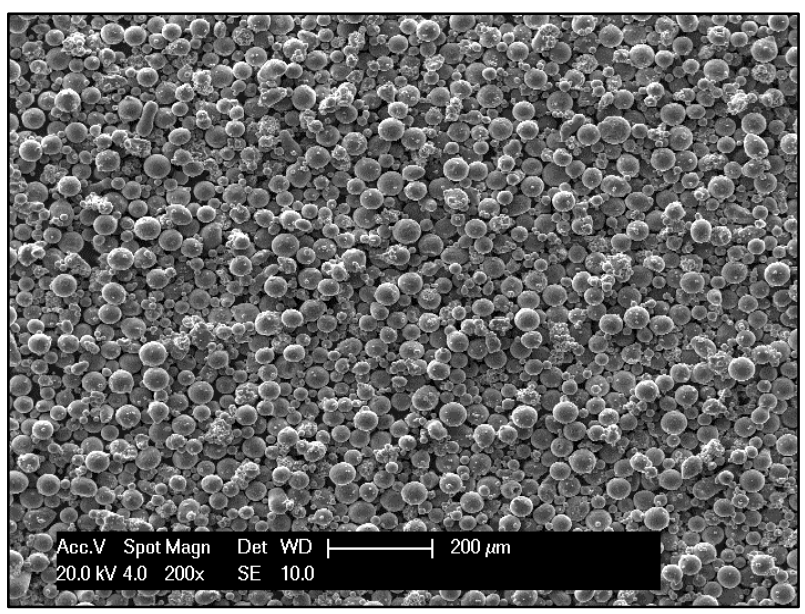

Figure 1: AlSi10Mg powder used in the study showing spherical morphology and minimal satellites.

The single track topography was examined using a Leica Schott KL1500 LCD microscope. The tracks were crosssectioned and polished according to the Struers protocol for metallographic preparations of aluminium alloys ${ }^{[13]}$. The geometrical features in terms of the depth and width of each melt pool were measured from scanning electron 
micrographs using the open source software Image J $1.46 \mathrm{r}^{[14]}$. The cross-sectioned scan tracks were etched using Keller's reagent $^{[15]}$ to reveal the microstructure of the selective laser melted material and imaged using a Nikon Eclipse LV100ND microscope. The chemical composition distribution in the cross-section of the melt pools was mapped using EDS. A MicroMaterials LTD (MML) Nanotest ${ }^{\mathrm{TM}}$ NTX Platform 2 nanoindenter was used to investigate the hardness profile across the melt pool of a scan track. The indentations spanned both the selective laser melted material and the ascast material. A Berkovich tip was used for indentation. Indenter tip shape factor was taken into account in the analysis as well as thermal drift pre and post indentation. Tests were performed in accordance with the ASTM standard E2546$07^{[16]}$ in a load-controlled mode. The maximum indentation load was set to $7.5 \mathrm{mN}$ and the spacing between each two adjacent indentations was $15 \mu \mathrm{m}$.

\section{RESULTS \& DISCUSSION}

The scan speed of $250 \mathrm{~mm} / \mathrm{s}$ is a relatively slow scan speed for processing AlSi10Mg using SLM ${ }^{[2]}$. This means that the exposure time to the laser beam at each point is significantly long. The scan tracks formed at such speed were observed to be free of major defects such as irregularities, discontinuities, or distortions, as can be seen in Figure 2(a). The presence of such defects in a scan track may increase the probability of pore formation when moving on to multi-track (to develop a layer) and multi-layer (to develop a part) processing. A laser beam focussed onto a metal substrate creates a cavity by ablation and plasma formation that is surrounded by molten material, applying forces on the cavity due to surface tension and hydrostatic pressures. As the laser beam moves in its assigned path, the melt pool material flows into the cavity and solidifies in a characteristic chevron pattern ${ }^{[1]}$. This characteristic chevron pattern is clearly shown in Figure 2(b). The chevron pattern denotes the direction of motion of the laser beam during processing in SLM. This is similar to the welds produced in laser welding ${ }^{[17]}$.
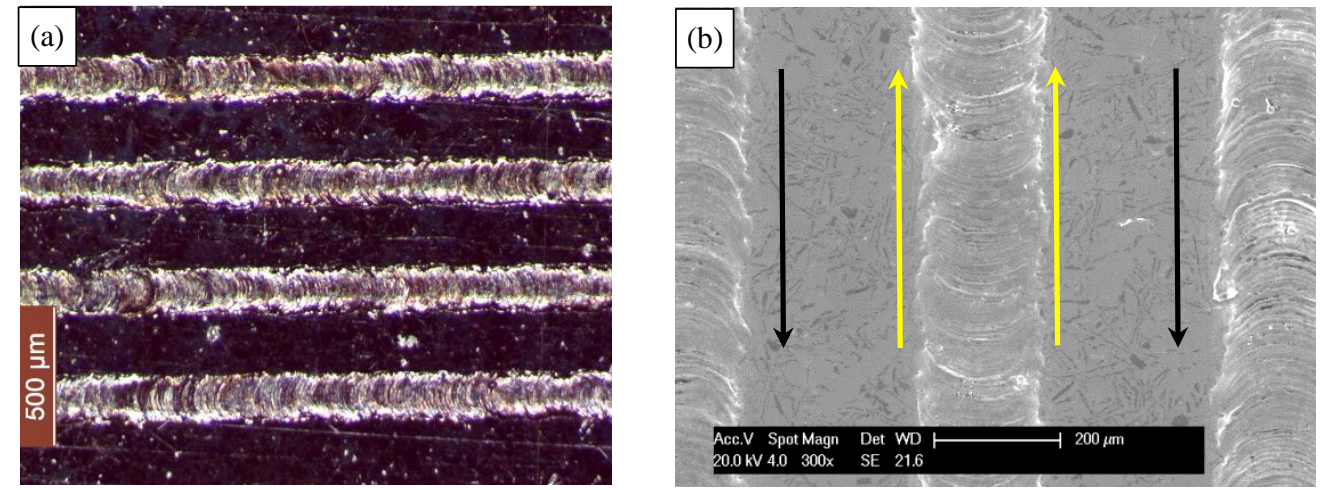

Figure 2: AlSi10Mg scan tracks (a) top view showing them to be free of discontinuities or irregularities and (b) with the characteristic chevron pattern denoting the scanning direction - shown by arrows.

The melt pool of a selective laser melted AlSi10Mg scan track was found to be conical as shown in Figure 3(a). This is different from the melt pools of scan tracks from other SLM candidate materials such as titanium alloys and stainless steels. The melt pools of the latter have been reported to have a spherical shape ${ }^{[6,10]}$. The shape of the melt pool is governed by the laser-material interactions. When a metallic material is irradiated by a laser beam, it melts either by conduction mode or keyhole mode melting. The mechanism depends on the energy transfer efficiency during the process. According to Zhao et al. ${ }^{[18]}$ the energy transfer efficiency is defined by the ratio between the laser energy absorbed by the target material and the originally irradiated laser power. If the energy transfer efficiency is equal to the material's absorptivity, conduction mode melting dominates. However, if the energy transfer efficiency is larger than the material's absorptivity due to high reflectivity and thermal conductivity within the melt pool, keyhole mode melting occurs. Keyhole mode melting results in a melt pool with a depth that is more than half its width ${ }^{[7]}$. The average width of the scan tracks in this study was $211.67 \pm 4 \mu \mathrm{m}$ measured at the widest region of the melt pool. The average overall height of the scan tracks (including both the depth of penetration below the substrate surface and the height above the substrate surface) was $238.33 \pm 7 \mu \mathrm{m}$. The larger depth of the melt pool compared to its width indicates keyhole mode melting rather than conduction mode melting. Keyhole mode melting implies that scan tracks of AlSi10Mg are 
susceptible to keyhole instabilities that may cause the formation of pores when producing bulk samples through multilayer processing.

The revealed microstructure in Figure 3(b) shows the melt pool to be made up of two grain structures. At the core of the melt pool, the grains are fine and equiaxed, however, the grains at the melt pool boundary are coarser and elongated. The elongation of the melt pool boundary grains is driven by the thermal gradient within the melt pool. A similar microstructural grain size and shape distribution has previously been observed in AlSi10Mg cubes fabricated by SLM, as reported by the authors ${ }^{[2]}$. The boundary of the melt pool is in contact with the solid Al substrate, which has lower thermal conductivity ${ }^{[19]}$ resulting in slower solidification at the boundary compared to the core. As a result, grains at the melt pool boundary are coarser than those at the core.
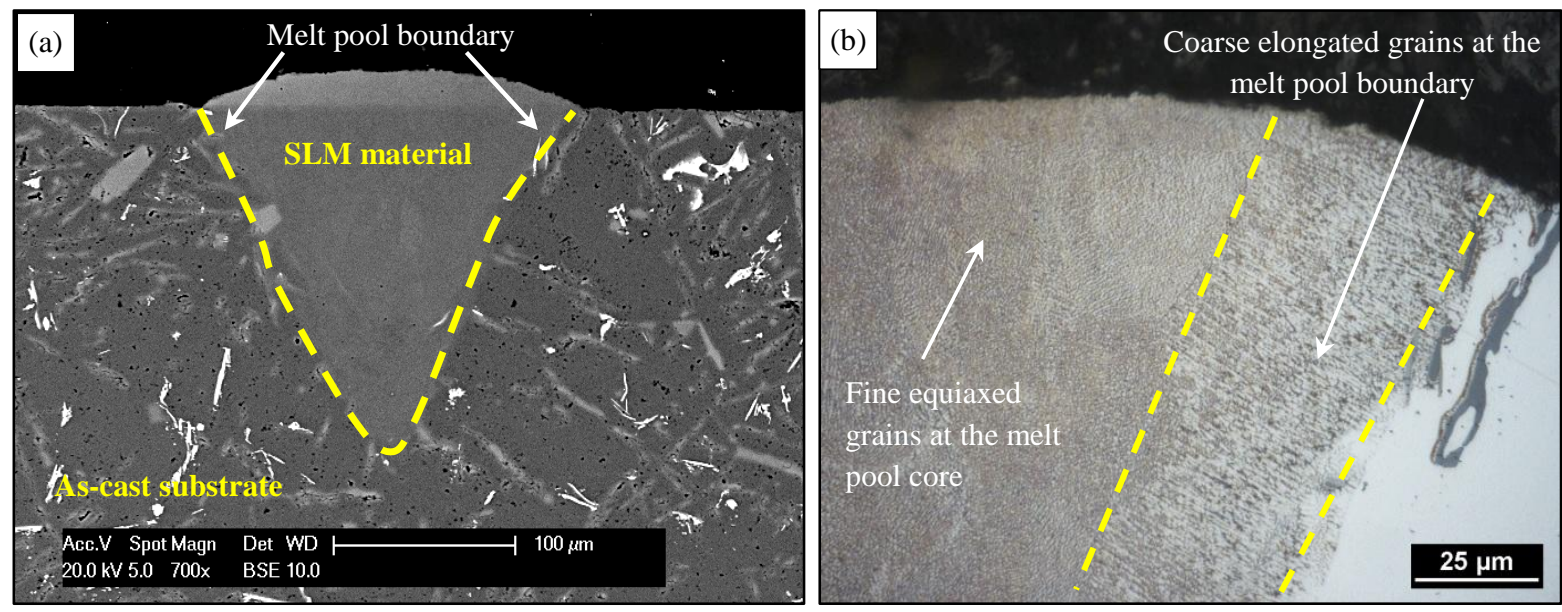

Figure 3: Cross-sectional view of (a) a polished and (b) an etched AlSi10Mg scan track.

During selective laser melting, the material melts and then solidifies at a fast rate. The rapid solidification results in an extremely fine microstructure ${ }^{[2]}$ as opposed to the coarse microstructure produced by casting. The difference in microstructure is clearly demonstrated in Figure 3(b). This is supported by comparing the chemical composition distribution in the selective laser melted material and the as-cast material, as shown in Figure 4. During solidification in casting, silicon had sufficient time for diffusion to form Si flakes. However, this did not occur in selective laser melting, so the material solidified with silicon finely dispersed in the aluminium matrix, segregated at the grain boundaries of the $\alpha$-Aluminium.

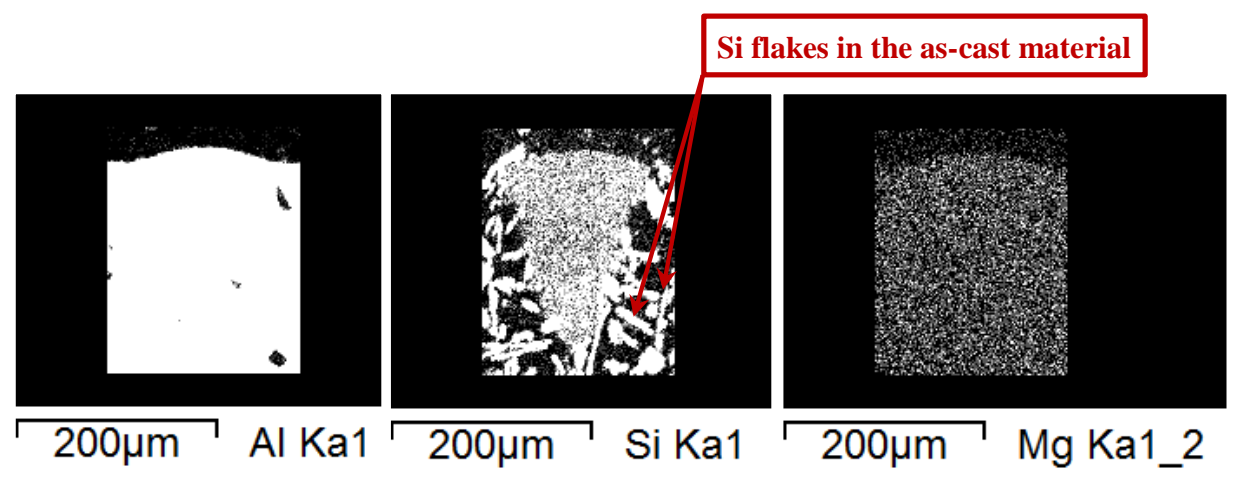

Figure 4: Mapping the chemical composition distribution of $\mathrm{Al}, \mathrm{Si}$, and $\mathrm{Mg}$ in a scan track.

The finer microstructure developed in the selective laser melted material is expected to yield improved mechanical properties when compared to conventionally manufactured material, e.g. through casting. This was evident in the nano- 
hardness profile across a melt pool of a scan track, as shown in the plot in Figure 5. The average nano-hardness in the ascast material was $0.97 \pm 0.03 \mathrm{GPa}$. The average nano-hardness in the selective laser melted material was $2.2 \pm 0.1 \mathrm{GPa}$. This means that an almost doubled nano-hardness is achieved via selective laser melting owing to the characteristically fine microstructure and the fine dispersion of the alloying elements. It is worth noting that none of the indentations on the as-cast material were coincident with a silicon rich flake. Indentations on the silicon rich flakes showed an average nano-hardness of $9 \pm 1 \mathrm{GPa}$, so they were excluded from the average nano-hardness. This shows that there is spatial variation in hardness in the as-cast material at the microstructural level. The finer homogenous microstructure in the selective laser melted material, however, provides a more uniform hardness profile. The indentations on the melt pool boundary (the first and last indentations within the melt pool) showed higher hardness than the core of the melt pool. This was seen to be high due to proximity to the silicon flakes in the as-cast material upon investigation with the optical microscope (shown in the inset in Figure 5).

There are a number of strengthening mechanisms in the selective laser melted material under investigation, namely, grain size reduction, solid solution strengthening, and dislocation strengthening ${ }^{[20]}$. The grain size reduction is governed by the Hall-Petch equation where strengthening occurs due to the increased fraction of grain boundaries hindering the motion of dislocations ${ }^{[21]}$. The grain size reduction in the selective laser melted material is achieved by rapid solidification. The solid solution strengthening is due to the presence of the alloying elements ${ }^{[2]}$ and dislocation strengthening is due to the presence of the density of dislocations. High densities of dislocations in SLM materials have been previously observed and attributed to the rapid cooling rates ${ }^{[23]}$. The effect of these strengthening mechanisms in SLM compared to cast material explains the enhanced nano-hardness in the selective laser melted material.

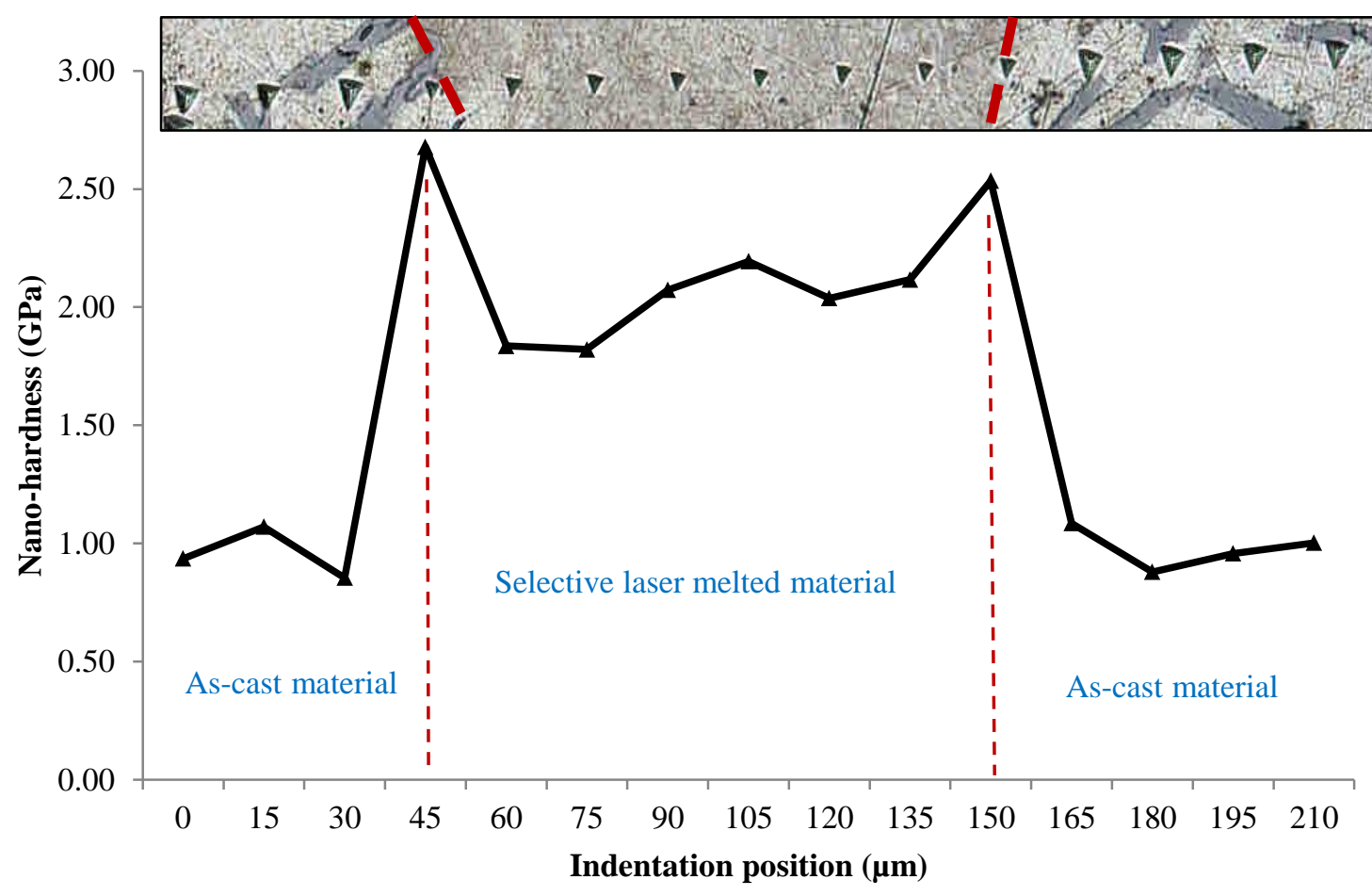

Figure 5: Nano-hardness profile of a line positioned at half the maximum height of a scan track spanning across both the selective laser melted material and the as-cast material.

The cross-sections of all scan tracks produced in this study showed no evidence of either metallurgical or keyhole pores, the two common types of pores seen in selective laser melting ${ }^{[2]}$. The presence of relatively high silicon content reduces the surface tension of aluminium and increased its fluidity ${ }^{[24]}$ leading to better flow of material and reducing the probability of pore formation. However, the possibility of pore formation using this combination of processing 
parameters cannot be eliminated since Aboulkhair et al. ${ }^{[2]}$ used the same set up and parameters to produce bulk samples and the parts suffered from an extensive presence of metallurgical pores. This confirms that pores are formed either during the overlap of single tracks to form a 3D part, i.e. during the re-melting of material. Tracing the formation of pores at each stage of processing requires further investigation.

\section{SUMMARY \& CONCLUSIONS}

Selective laser melting of AlSi10Mg using relatively slow scan speeds has successfully produced consolidated single tracks that are free of defects. The depths and widths of the tracks created indicate that keyhole mode melting dominates the melting and solidification process during the selective laser melting of AlSi10Mg. Keyhole mode melting introduces the possibility of keyhole instabilities that might lead to porosity formation. However, pores were not observed in any of the tracks produced in this study. Rapid cooling and solidification in the process yield a fine microstructure with good dispersion of the alloying elements within the base metal. This characteristically fine microstructure caused the selective laser melted material to show higher average nano-hardness compared to the as-cast material, with the latter also demonstrating variation in hardness dependant on the indented phase.

\section{ACKNOWLEDGMENTS}

Nesma T. Aboulkhair gratefully acknowledges funding provided by the Dean of Engineering Scholarship for International Research Excellence, Faculty of Engineering, University of Nottingham, United Kingdom.

\section{REFERENCES}

[1] Ion, J. C., [Laser processing of engineering materials: Principles, Procedure, and Industrial application], Elsevier, United Kingdom (2005).

[2] Aboulkhair, N. T., Everitt, N. M., Ashcroft, I., and Tuck, C., "Reducing porosity in AlSi10Mg parts processed by selective laser melting", Additive Manuf. 1-4 (0), 77-86 (2014).

[3] Krauss, H., and Zaeh, M. F., "Investigations on manufacturability and process reliability of selective laser melting", Phys. Procedia 41(0), 815-822 (2013).

[4] Kempen, K., Thijs, L., Yasa, E., Badrossamay, M., Verheecke, W., and Kruth, J-P., "Process optimization and microstructural analysis for selective laser melting of AlSi10Mg," (2011).

[5] Kempen, K., Thijs, L., Van Humbeeck, J., and Kruth, J. P., "Processing AlSi10Mg by selective laser melting: parameter optimisation and material characterisation," Mater. Sci. and Technol. (2014).

[6] Yadroitsev, I.. Gusarov, A., Yadroitsava, I., and Smurov, I., "Single track formation in selective laser melting of metal powders," J. Mater. Process. Technol. 210(12), 1624-1631 (2010).

[7] King, W. E., Barth, H. D., Castillo, V. M., Gallegos, G. F., Gibbs, J. W., Hahn, D. E., Kamath, C., Rubenchik, A. M., Observation of keyhole-mode laser melting in laser powder-bed fusion additive manufacturing," J. Mater. Process. Technol. 214(12), 2915-2925 (2014).

[8] Yadroitsev, I., Bertrand, P., and Smurov, I., "Parametric analysis of the selective laser melting process," Appl. Surf. Sci. 253(19), 8064-8069 (2007).

[9] Kamath, C., El-dasher, B., Gallegos, G. F., King, W. E., and Sisto, A., "Density of Additively-Manufactured, 316L SS Parts Using Laser Powder-Bed Fusion at Powers Up to 400W,” Int. J. Addit. Manuf. Techol. (2013).

[10] Yadroitsev, I., Krakhmalev, P., Yadroitsava, I., Johansson, S., and Smurov, I., "Energy input effect on morphology and microstructure of selective laser melting single track from metallic powder," J. Mater. Process. Technol. 213(4), 606-613 (2013). 
[11] Dai, D. and Gu, D., "Thermal behavior and densification mechanism during selective laser melting of copper matrix composites: Simulation and experiments," Mater. Design 55(0), 482-491 (2014).

[12] http://www.steelnumber.com/en/steel_alloy_composition_eu.php?name_id=1227, cited June $17^{\text {th }} 2014$.

[13] Weidmann, E. and Guesnier, A., "Struers Application Notes: Metallographic preparation of aluminium and aluminium alloys," (2008).

[14] Abramoff, M.D., Magalhaes, P. J., and Ram, S. J., "Image Processing with ImageJ,” J. Biophotonics Int.11(7), 7 (2004).

[15] Voort, G.F.V., [Metallography: Principles \& practice], ASM International, United States of America (1999).

[16] ASTM E2546-07, Standard Practice for Instrumented Indentation Testing, ASTM International, West Conshohocken, PA, 2007, www.astm.org.

[17] Haboudou, A., Peyre, P., Vannes, A. B., and Peix, G., "Reduction of porosity content generated during Nd:YAG laser welding of A356 and AA5083 aluminium alloys," Mater. Sci. Eng. A 363(1-2), 40-52 (2003).

[18] Zhao, H., White, D. R., and DebRoy, T., "Current issues and problems in laser welding of automotive aluminium alloys," Int. Mater. Rev. 44(6), 238-266 (1999).

[19] Baudouy, B. and Four, A, "Low temperature thermal conductivity of aluminum alloy 5056," Cryogenics 60, 1-4 (2014).

[20] Ma, K.,Wen, H., Hu, T., Topping, T. D., Isheim, D., Seidman, D. N., Lavernia, E. J., and Schoenung, J. M., "Mechanical behavior and strengthening mechanisms in ultrafine grain precipitation-strengthened aluminum alloy," Acta Mater. 62(0), 141-155 (2014).

[21] Choi, H. J., Lee, S. W., Park, J. S., and Bae, D. H., "Tensile behavior of bulk nanocrystalline aluminum synthesized by hot extrusion of ball-milled powders," Scripta Mater. 59(10), 1123-1126 (2008).

[22] Callister, W. D. and Rethwisch, D. G., [Materials Science and Engineering: An introduction], John Wiley and Sons (2010).

[23] Song, B., Dong, S., Deng, S., Liao, H., and Coddet, C., "Microstructure and tensile properties of iron parts fabricated by selective laser melting," Opt. Laser Technol. 56, 451-460 (2014).

[24] Kempen, K., Thijs, L., Van Humbeeck, J., and Kruth, J.P., "Processing AlSi10Mg by selective laser melting: parameter optimisation and material characterization," Mater. Sci. Tech. 